\title{
Flat plate solar air heater with helical integrated fins for drying processes
}

\author{
Al-Neama, M. A. ${ }^{\text {a }}$; Farkas, I. $^{\mathbf{6}}$ \\ a Mechanical Engineering Doctoral School. Szent István University, Gödöllö, Hungary \\ b Department of Physics and Process Control. Szent István University, Gödöllö,Hungary \\ *E-mail of the corresponding author: Farkas.Istvan@gek.szie.hu
}

\begin{abstract}
In this study, an experimental investigation was carried out on solar system consists of many main components; solar air collector, drying chamber and air blower. Manufacturing and an analysis of two active double-pass solar air collector integrated with unfinned and helical finned absorbers have been carried out. The helical fins increased the standers solar collector (unfinned) efficiency by about $6 \%$. In five hours for $2 \mathrm{~kg}$ of apple slices drying, the final weight of the dried product is $1.237 \mathrm{~kg}$ using an unfinned solar collector, while $1.039 \mathrm{~kg}$ using helical finned solar collector.
\end{abstract}

Keywords: solar drying, air heater, thermal performance, helical fins. 


\section{Introduction}

Drying is a complicated process including the transient transfer of mass and heat with several rate processes, such as physical or chemical transformations, which, in turn, may cause changes in product quality as well as the mechanisms of heat and mass transfer [1].

Air heater is the essential equipment through which solar energy is converted into heat energy. However, how to increase the thermal efficiency of solar air heaters becomes a significant challenge. In this paper, the design of different solar air heater with different absorber plate is discussed. Many parameters are affecting significantly on thermal performance of the solar collector, such as area of absorber, shape of absorber, speed of air, number of flow passes, number of glasses, material of absorber,..., etc. The major parameters which discussed in this paper is the absorber shape and absorber area. Solar air collectors are classified basically into two types: bare plate and cover plate solar air heaters.

The bare plate solar air heaters consist simply of an air duct, the upper surface of which operates as the solar-energy absorber plate and the back surface insulated. For coveredplate solar air-heating collectors, to reduce upward heat losses from solar air heaters transparent cover materials above and usually parallel to the absorber plate are used of one or more [2]. The performance of solar collectors under low-temperature conditions measured and simulated. The experimental results showed that for temperatures below ambient and for cases without irradiance, unglazed collectors performed better than glazed ones, with considerable heat gains from condensation and frost. The glazed collectors are not suitable to operate at temperatures below the dew point as condensation and frost conditions might lead to deterioration of materials, compromising the reliability and durability of this type of collector [3].

The performance of a double pass solar air heater tested in the previous studies, and the results showed that the thermal efficiency of double pass solar air collector with the porous material is $20-25 \%$ and $30-35 \%$ higher than that of double-pass solar collector without porous material and single pass collector respectively [4]. The effect of the cross-sectional configurations on the thermal performance of the plastic solar air heater is examined. The results indicated that the highest efficiency was achieved for the circular shape about $80 \%$ at a flow rate of $0.18 \mathrm{~kg} / \mathrm{s}$ and average solar radiation of $925 \mathrm{~W} / \mathrm{m}^{2}$ [5]. The solar radiation incident on solar collector has little effect on the efficiency of the collector, although it has a significant impact on the ambient air temperature around the collector. The outlet air temperature in flow channel increases almost linearly with insolation [6].

According to the above brief review for past literature, in the recent paper, manufacturing, and analysis of active double-pass solar air collector integrated with helical shaped finned absorber is done to be carried out. 


\section{Materials and Methods}

In this study, an experimental investigation was carried out on solar system consists of many principal components to achieve study goals. The solar system includes mainly of solar air heater, drying cabin and inline air blower. Insulated air ducts have connected the elements. The system designed, manufactured and tested in the laboratory of the Department of Physics and Process Control, Szent István University, Gödöllő, Hungary.

\subsection{Solar air collector}

A simple double air-pass solar air collector had been manufactured with $120 \times 50 \times 15 \mathrm{~cm}$ length, width and thickness (external dimensions) respectively. The outer case of solar air collector is made from wood sheets and bars with different thicknesses with dimensions. For study purpose, two absorbing surfaces are made from copper sheet with $1.5 \mathrm{~mm}$ thickness and thermal conductivity $385 \mathrm{~W} / \mathrm{mK}$ (see Fig. 1). A black matt paint used to enhance these surfaces properties (selective surface). A polystyrene material with thermal conductivity $0.038 \mathrm{~W} / \mathrm{mK}$ is used as back insulation. Back insulation thickness is $2 \mathrm{~cm}$, and dimensions are $120 \times 50 \mathrm{~cm}$ length and width respectively. The sides of the body were well insulated to prevent heat loss by using self-adhesive rubber foam tape with a thickness of 3 $\mathrm{mm}$. A transparent cover fixed on the top edges of the collector wood case and thermal insulation at the bottom base side of the wooden case. A $4 \mathrm{~mm}$ thick plastic glass sheet used to cover solar collector.
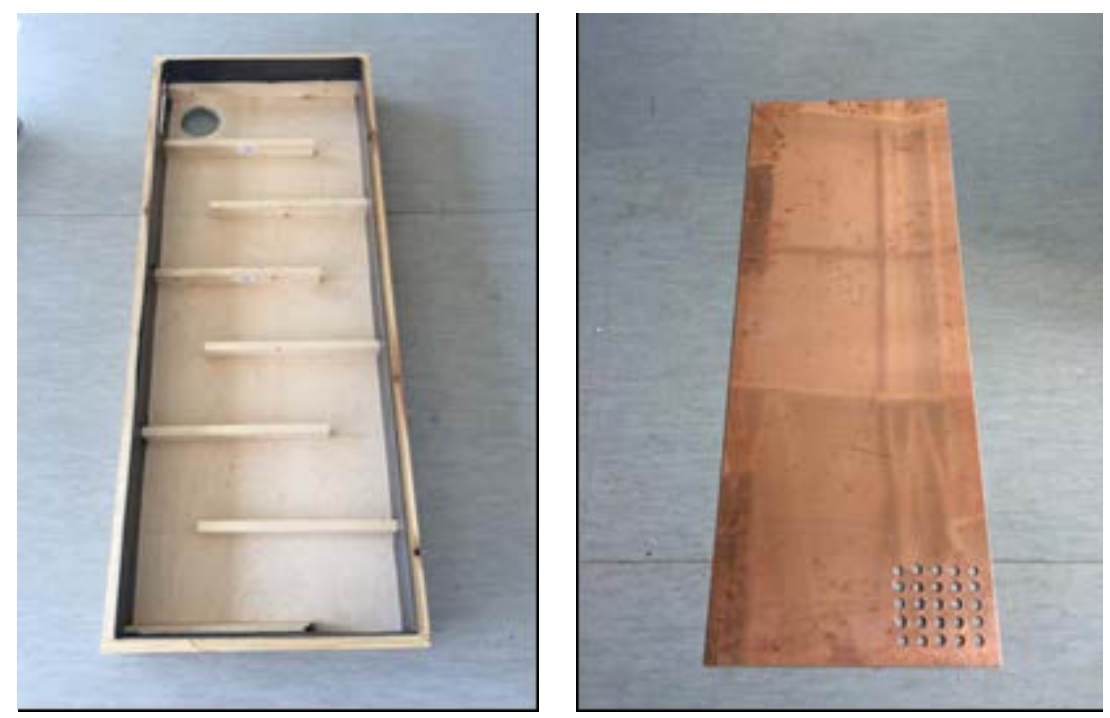

Fig. 1. Wooden case and absorbing surface of solar air heater 
The first absorber is flat absorber (un-finned) with dimensions $46.2 \times 121.8 \mathrm{~cm}$, while the second absorber had made with the same aspects of the first surface with helical Aluminum fins to increase its area of surface. The dimensions of attached fins are shown in Fig. 2. Fins function is expanding air streams length with the absorber surface to improve the useful heat transfer to the air. The space between every two buffers is $17 \mathrm{~m}$. Areas of air heater inlet, exit and second channel entrance are the same, to avoid pressure reduction through the solar collector.

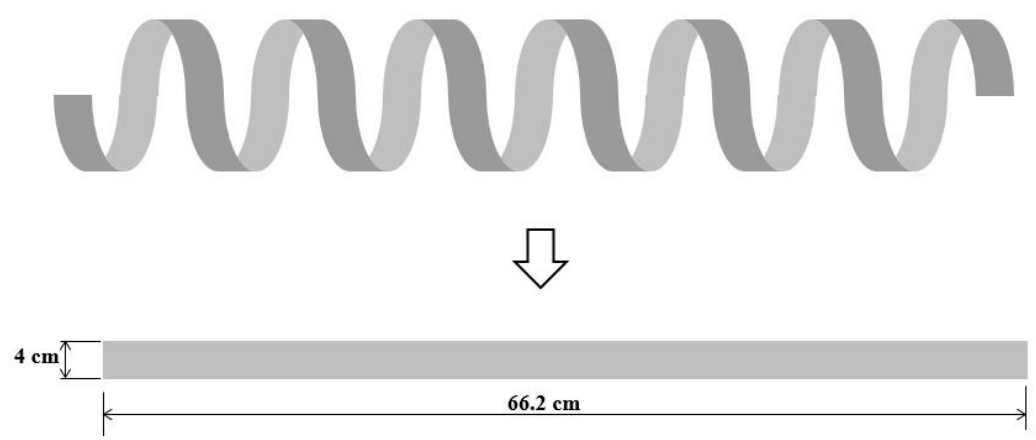

Fig. 2. Helical extended surfaces dimensions

The air recirculated from first to second air channel through 25 holes, which made on the absorber. Second air channel designed using many wood buffers which fixed on the back surface of a solar collector as shown in Fig. 1. Air circulates through the solar collector, inline air blower in air duct between solar heaters and surrounding has been used. According to Duffie and Beckman, flat-plate solar collector tilted in a way that it receives maximum solar radiation during the day and to be perpendicular to solar radiation rays at noon. The best stationary orientation is due South in the northern hemisphere and due North in the southern hemisphere. Therefore, the two solar air heaters in this work are oriented facing South line and tilted at 45o to the horizontal according to the solar chart for Budapest region (Budapest 47.5。 N, 19.05。 E) [7].

\subsection{Drying cabin}

The drying chamber is made with five trays where the different products items are placed. The external chamber dimensions are $50 \times 50 \times 100 \mathrm{~cm}$ length, width, and height respectively, as shown in Fig. 3. Dryer walls have been made from polystyrene with $5 \mathrm{~cm}$ thickness and thermal conductivity $73 \mathrm{~W} / \mathrm{mK}$, except the front wall of chamber made from 
$4 \mathrm{~mm}$ plastic glass sheet for observing. The five trays made from plastic nets and fixed with $10 \mathrm{~cm}$ distance between each. The chamber integrated with the solar air heater by a small duct (indirect drying) with $10 \mathrm{~cm}$ diameter.

All air leakages from drying space closed totally as possible. The product sample which used through this study is apple. Apple selected as a sample because of its high initial moisture content and its high maximum allowable temperature. The initial moisture content and maximum allowable temperature for an apple during drying process are $80 \%$ (wet base) and $70{ }^{\circ} \mathrm{C}$ respectively [8].
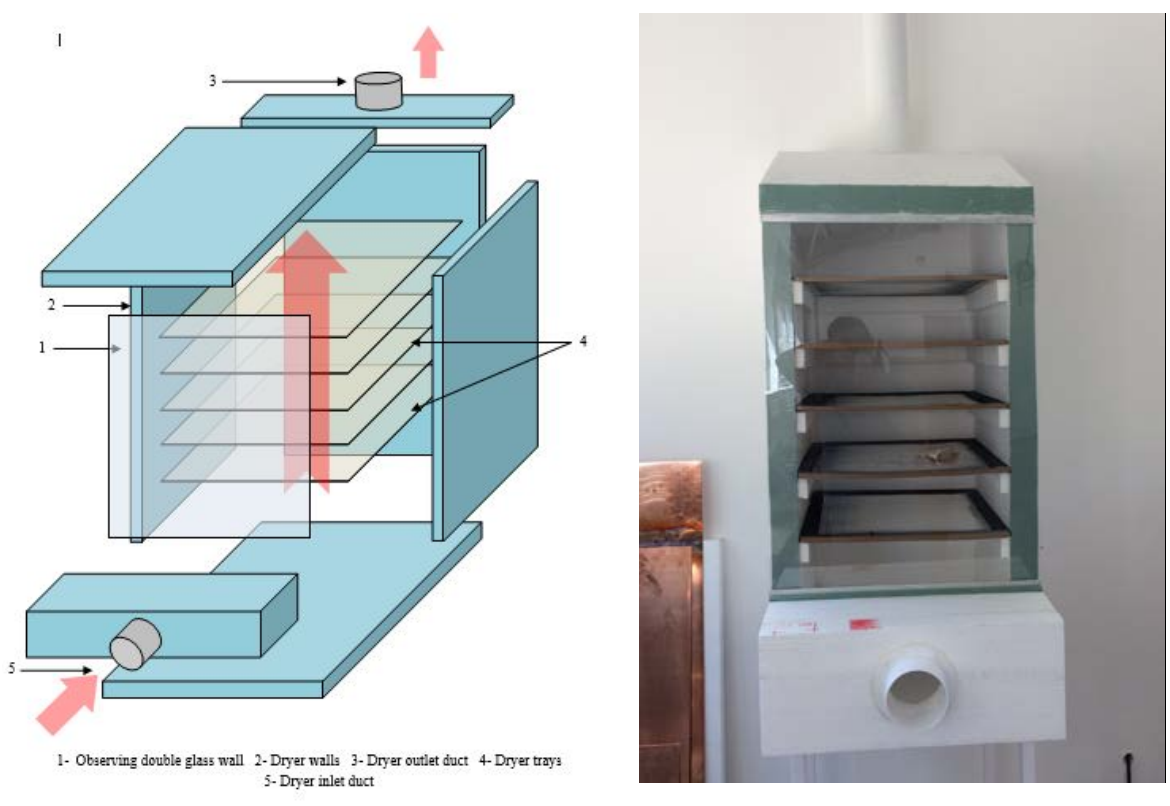

Fig. 3. Layout of drying chamber

\section{Results}

Two sets of results are collected, the first set shows the experimental results of the double air pass unfinned solar heater test, the second set shows the experimental results of double air pass helical finned solar heater test. Airspeed for these tests is $2.3 \mathrm{~m} / \mathrm{s}$ with air duct cross-section area $0.00635 \mathrm{~m}^{2}$. Properties of air which considered for performance calculations are $1.2 \mathrm{~kg} / \mathrm{m}^{3}$ and $1000 \mathrm{~J} / \mathrm{kgK}$ density and air specific heat at constant pressure respectively. The tests carried out on $2^{\text {nd }}$ and $9^{\text {th }}$ of October 2017 . The daily efficiency for unfinned solar collector was $54.8 \%$. The helical fins increased the standers solar collector 
efficiency by about 6\%. Fig. 4 and Fig 5 showed the relative humidity and temperature stratification in drying chamber by using unfinned solar air collector. Fig. 6 and Fig 7 showed the relative humidity and temperature stratification in drying chamber by using helical finned solar air collector.

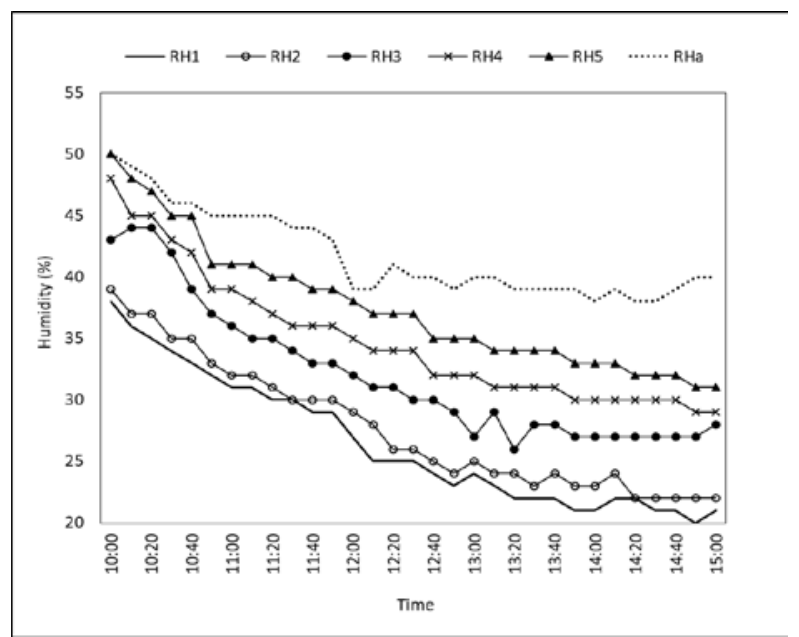

Fig. 4. Relative humidity distribution in drying chamber by using unfinned collector

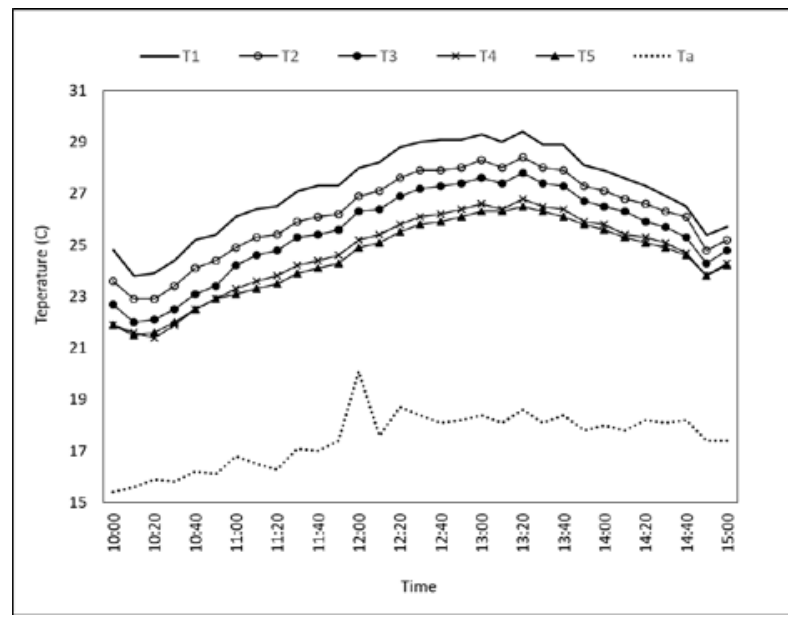

Fig. 5. Temperature distribution in drying chamber by using unfinned collector 
It is clear that the product loses of its moisture in a short time at the beginning of the process, and much time is needed for the remaining water content to be lost. Humidity stratification is more obvious with using unfinned collector. In five hours for $2 \mathrm{~kg}$ of apple slices drying, the final weight of the dried product is $1.237 \mathrm{~kg}$ using an unfinned solar collector, while $1.039 \mathrm{~kg}$ using helical finned solar collector.

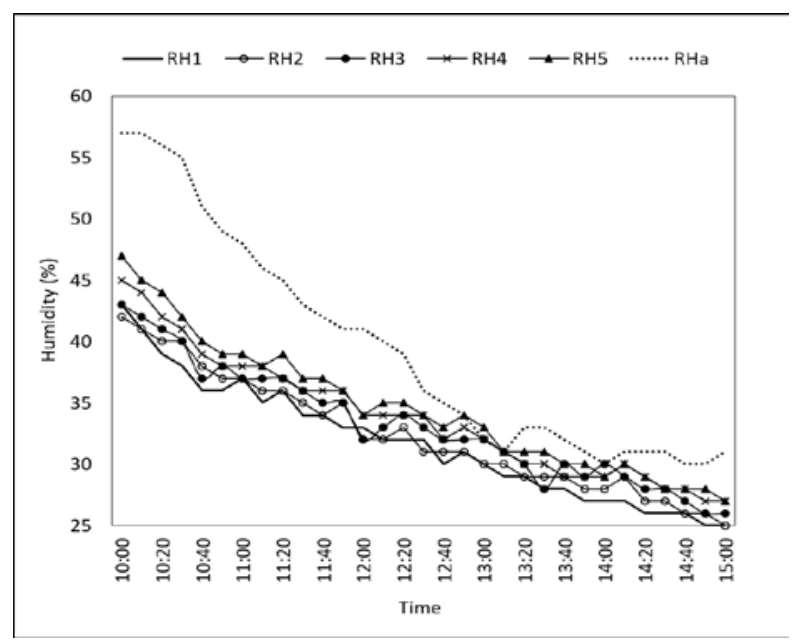

Fig. 6. Relative humidity distribution in drying chamber by using helical finned collector

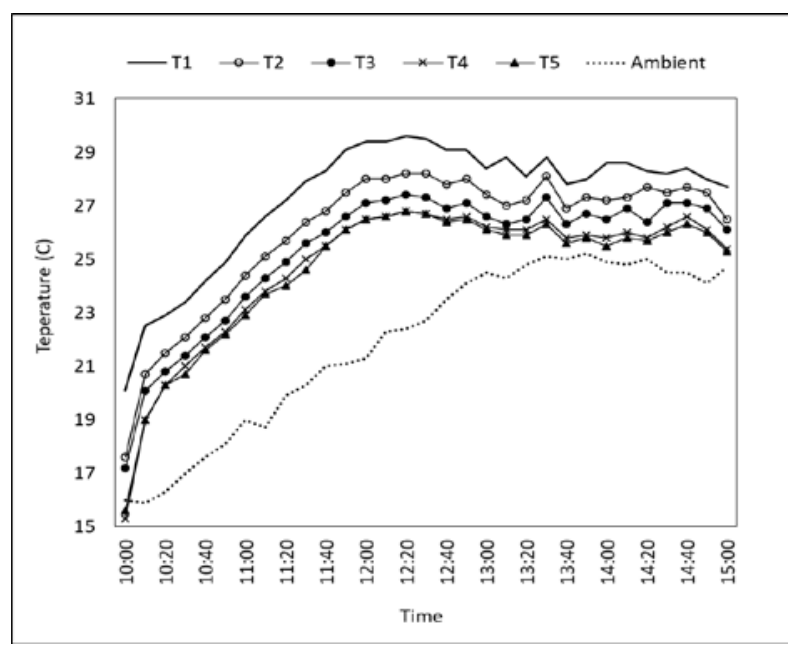

Fig. 7. Temperature distribution in drying chamber by using helical finned collector 


\section{Conclusions}

1. The daily efficiency for unfinned solar collector was $54.8 \%$.

2. The helical fins increased the standers solar collector efficiency by about $6 \%$.

3. In five hours for $2 \mathrm{~kg}$ of apple slices drying, the final weight of the dried product is $1.237 \mathrm{~kg}$ using an unfinned solar collector, while $1.039 \mathrm{~kg}$ using helical finned solar collector.

4. The costs of designing and manufacturing process of solar drying system are low compared with other drying methods.

5. The maintenaces costs are uncomplicated and cheap.

6. Clean process with low electricity consumption.

\section{References}

[1] Neményi, M.; Farkas, I.; Czaba, I.; Kovács, A. Drying characteristics of maize hybrids' components. Hungarian Agricultural Engineering 1994, 7, 40-41.

[2] Ekechukwu, O.; Norton, B. Review of solar-energy drying Systems II: an overview solar drying technology. Energy Conversion and Management Journal 1999, 40, 615655.

[3] Bunea, M.; Eicher, S.; Hildbrand, C.; Bony, J.; Perers, B.; Citherlet, S. Performance of solar collectors under low temperature conditions: Measurements and simulations results. Paper presented at Eurosun, 2012, Rijeka, Croatia.

[4] Ramani, B.M.; Gupta, A.; Kumar, R. Performance of a double pass solar air collector. Solar Energy 2010, 84, 1929-1937.

[5] Abdullah, A.S.; El-Samadony, Y.A.F; Omara, Z.M. Performance evaluation of plastic solar air heater with different cross sectional configuration. Applied Thermal Engineering 2017, 121, 218-223.

[6] Rai, S.; Chand, P.; Sharma, S.P. An analytical investigations on thermal and thermohydraulic performance of offset finned absorber solar air heater. Solar energy 2017, 153, 25-40.

[7] Duffie, J.; Beckman, W. Solar Engineering of Thermal Processes. Fourth edition, John Wiley \& Sons, New Jersey. USA, 2013.

[8] Sharma, A.; Chen, C.R.; Lan, N.V. Solar-energy drying systems: A review, Renewable and Sustainable Energy Reviews Journal 2009, 13, 1185-1210. 